\title{
Funkhouseriana, um novo gênero de Darninae (Hemiptera, Membracidae) ${ }^{1}$
}

\author{
Antonio José Creão-Duarte ${ }^{2}$
}

\begin{abstract}
Funkhouseriana, a new genus of Darninae (Hemiptera, Membracidae). Funkhouseriana gen.n. is described (type species Tynelia cerulea Funkhouser, 1935). Funkhouseriana cerulea, comb.n. is redescribed and illustrated.

KEY WORDS. Hemiptera, Membracidae, Darninae, Funkhouseriana gen.n., taxonomy
\end{abstract}

FUNKHOUSER (1935) descreveu Tynelia cerulea enquadrando-a erroneamente em Smiliinae. Recentemente, trabalhando com as espécies de Tynelia (Stål, 1858), verificou-se que $T$. cerulea pertence a Darninae-Darnini pelo tipo de venação das tégminas, isto é, com a terceira célula apical truncada, estando presente a transversa s-m e pelo pronoto grandemente desenvolvido, cobrindo parcialmente as tégminas. Provavelmente, devido a forma com que se apresenta a terceira célula apical com a porção distal marcadamente expandida tomando a forma mais ou menos triangular, fez com que Funkhouser a incluísse em Smiliinae. METCALF \& WADE (1965) mantiveram-na com a combinação original, dentro de Smiliinae, e na tribo Polyglyptini. DeITz (1975), por sua vez, analisando outros caracteres, colocou-a em Amastrini. Pelos motivos acima expostos e verificando que as características apresentadas por $T$. cerulea não permitem posicioná-la em nenhum dos gêneros conhecidos de Darnini, achou-se por bem descrever um novo gênero para acomodá-la.

CREÃo-DuARTE (1998) apresentou no XXII Congresso Brasileiro de Zoologia, em Recife, Pernambuco, uma nota comentando que estava criando um novo gênero para T. cerulea denominado de Funkhouseriana. Essa nota saiu publicada no livro de Resumos do referido congresso. O nome Funkhouseriana entretanto, não se tornou disponível por este fato uma vez que não foi acompanhado de uma descrição e nem da designação da espécie-tipo (ICZN 1985: Art. 13 a-i,b). Considerou-se, portanto, Funkhouseriana Creão-Duarte, 1998, um nomen nudum.

Abreviaturas usadas no texto: (DZUP) Departamento de Zoologia, Universidade Federal do Paraná, Coleção de Entomologia Pe. J.S. Moure; (BMNH) The Natural History Museum, Londres.

1) Contribuição número 1146 do Departamento de Zoologia, Universidade Federal do Paraná.

2) Departamento de Sistemática e Ecologia, Universidade Federal da Paraíba, Campus I. 58059-900 João Pessoa, Paraíba, Brasil.

E-mail: creao@dse.com.br 


\section{Funkhouseriana, gen.n.}

Funkhouseriana Creão-Duarte, 1998: 127 (nomen nudum).

Espécie-tipo: Tynelia cerulea Funkhouser, 1935.

Cabeça subtriangular, mais larga que longa, obliquamente projetada para frente; olhos globosos, pouco salientes; vértice convexo, levemente rugoso-pontuado, margem superior arqueada; ocelos conspícuos situados logo acima da linha imaginária que passa pelo centro dos olhos, equidistantes dos mesmos e entre si e da margem superior; lóbulos supra-antenais foliáceos, com as margens levemente sinuosas; pós-clípeo mais ou menos ovóide, transversalmente rugoso e densamente piloso no ápice; anteclípeo relativamente pequeno, em vista lateral formando um ângulo reto com o pós-clípeo; rostro atingindo os mesotrocanteres. Pronoto largamente convexo, fortemente impresso lateralmente depois dos ângulos umerais, posteriormente inflado, abruptamente afilado, tectiforme e acuminado, terminando antes do ápice das tégminas; lóbulos pós-oculares ajustados ao corpo, com uma curta carena na altura do ângulo posterior dos olhos; ângulos umerais levemente projetados sobre os úmeros, obtusos, ocultando, em vista superior, a articulação das tégminas. Tégminas parcialmente cobertas pelo pronoto; veia $\mathbf{S}$ bifurcada bem depois do meio; veias $\mathbf{M}$ e $\mathbf{C u}$ unidas junto à base; com duas células discoidais e cinco apicais, sendo a terceira abruptamente alargada distalmente; transversas $\mathbf{s}$, $\mathbf{s}-\mathbf{m}$, e duas $\mathbf{m}-\mathbf{c u}$ presentes. Asas com quatro células apicais, a primeira mais ou menos fusiforme; lóbulo jugal pequeno. Pernas normais, com tíbias prismáticas.

Comentários. Este gênero fica próximo de Taunaya Fonseca, 1934 e de Cyphotes Burmeister, 1835, na sua forma geral. O pronoto é liso e brilhante ao contrário dos outros dois, que são grosseiramente pontuados, observando-se ainda, linhas elevadas ou carenas. O pronoto em Funkhouseriana gen.n., cobre parcialmente as tégminas, aproximadamente $1 / 3$, e o ápice não atinge $o$ final das tégminas.

Etimologia. O nome genérico é em homenagem a W.D. Funkhouser, autor de inúmeros trabalhos sobre Membracidae.

\section{Funkhouseriana cerulea (Funkhouser, 1935) comb.n.}

\section{Figs 1-3}

Tynelia cerulea Funkhouser, 1935: 434 (Loc.-tipo: Guiana). - Metcalf \& Wade, 1965: 883. - Broomfield, 1971: 339. - Creão-Duarte, 1998: 127.

Medidas (mm). Fêmea/macho. Comprimento total 8,36/7,00; distância entre os ângulos umerais 4,27/3,60; largura da cabeça 3,13/2,85.

Macho. Colorido geral azul-escuro com brilho metálico azul-esverdeado; tégminas escurecidas ao longo das veias, principalmente perto da margem costal. Cabeça subtriangular, fortemente defletida para frente. Pronoto brilhante, discretamente pontuado, glabro; largamente convexo, em vista dorsal fortemente comprimido lateralmente atrás dos ângulos umerais, depois inflado em um bulbo bilobado posteriormente; margens laterais encobrindo aproximadamente um terço das tégminas; porção látero-posterior após a formação bulbosa, abruptamente truncada formando, de cada lado, um canto em ângulo quase reto; porção distal tectiforme e 


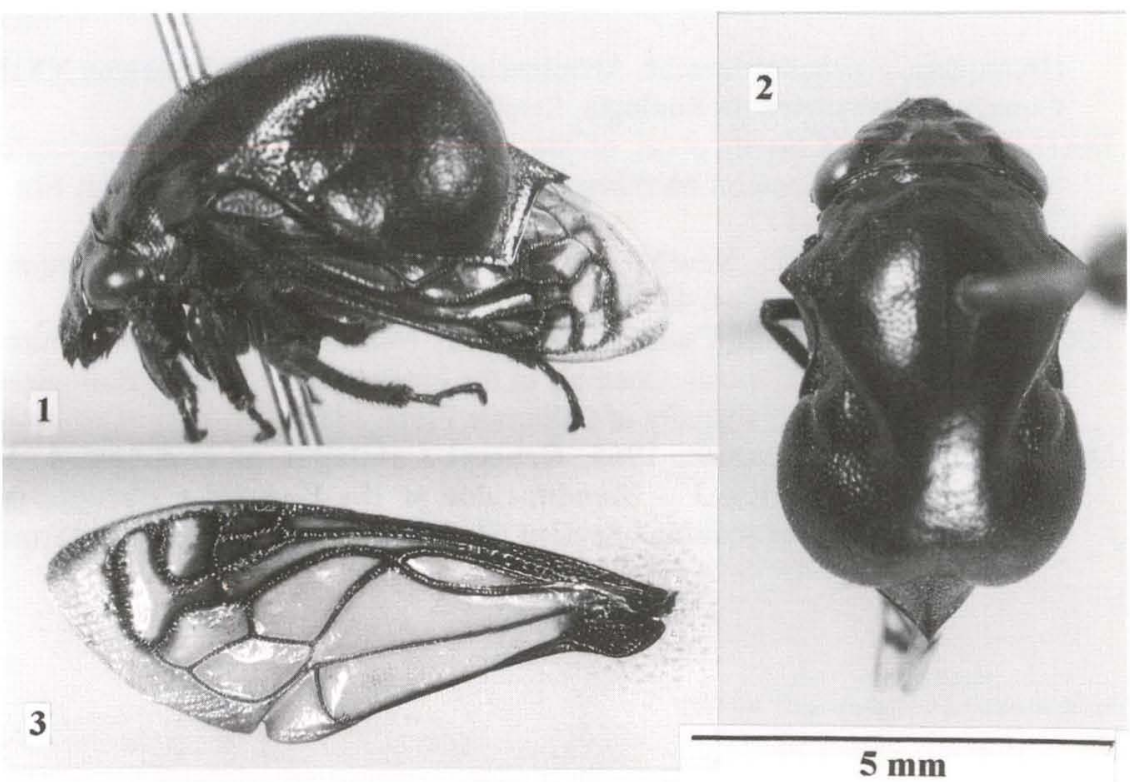

Figs 1-3. Funkhouseriana cerulea. (1-2) macho, vistas lateral e dorsal; (3) tégmina.

acuminada, estendendo-se até o final da quarta célula apical. Pernas pilosas com tíbias prismáticas e carenadas lateralmente. Tégminas com cinco células apicais e duas discoidais; o ramo $\mathbf{S}_{\mathbf{2}}$ atingindo a margem costal na altura da transversa $\mathbf{s}$; os ramos $\mathbf{S}_{\mathbf{3}+\mathbf{4}}$ e $\mathbf{M}_{\mathbf{1}+\mathbf{2}}$ curvados em sentidos opostos, tornando a terceira célula apical extremamente expandida na parte distal; $\mathbf{C u}$ curvada fortemente em direção ao ápice do clavo, a partir da transversa m-cu. Asas com quatro células apicais.

Fêmea. Semelhante ao macho, diferindo nos seguintes aspectos: tamanho maior, pronoto com extremidade posterior atingindo o final da terceira célula apical.

Material examinado. Brasil, Mato Grosso: Vila Vera, 1 macho, X.1974, M. Alvarenga leg.; Sinop (12³1'S, 553' 'W), 2 machos, X.1975, M. Alvarenga leg.; ibidem, 1 macho e 1 fềmea, X.1995, M. Alvarenga leg. (DZUP).

Holótipo, macho. British GuIANA: Canister Falls, VI.1920. A.A. Abraham leg., depositado no The Natural History Museum, Londres (BMNH).

AGRADECIMENTOS. Ao CNPq pelo auxílio. À senhora Janet Margerison-Knight, pelo envio do holótipo e pela atenção dada a todos os nossos inúmeros pedidos. A Lewis L. Deitz e S.H. McKamey pelas críticas e sugestões.

\section{REFERÊNCIAS BIBLIOGRÁFICAS}

BRoOMFIELD, P.S. 1971. A Catalogue of the membracid types (Homoptera: Membracidae) in the British Museum (Natural History). Bull. British Museum (Natural History) Entomol. 25 (8): 327-386.

Creão-Duarte, A.J. 1998. Funkhouseriana, um novo gênero de Darnini 
(Hemiptera, Auchenorrhyncha, Membracidae, Darninae). In: Resumos XXII Congresso Brasileiro de Zoologia. Recife, Pernambuco, p.127.

DEITZ, L.L. 1975. Classification of the higher categories of the new world tree-hoppers (Homoptera: Membracidae). Bull. N. Carol. agric. Exper. Stn., Tech. Bull. 225: 1-177.

FUNKHOUSER, W.D. 1935. New Membracidae in the imperial Institute Collection. Jour. N.Y. Entomol. Soc. 43: 428-434.

ICZN. 1985. International Code of Zoological Nomenclature. Third Edition adopted by the XX General Assembly of the International Union of Biological Sciences. Berkeley, University of California Press, 338p.

Metcalf, Z.P. \& V. Wade. 1965. General Catalogue of Homoptera. A supplement to Fascicle I - Membracidae of the General Catalogue of Hemiptera. Membracoidea. Section II. Raleigh, North Carolina State University, p. 741-1555.

Recebido em 07.V.1998; aceito em 27.VIII.1999 